\title{
Indwelling Pleural Catheters for Ambulatory Out-Patient Care: A Price Worth Paying?
}

\author{
Rahul Bhatnagar Nick Maskell \\ Academic Respiratory Unit, School of Clinical Sciences, University of Bristol, Learning and Research Building, \\ Southmead Hospital, Bristol, UK
}

The development of the indwelling pleural catheter (IPC) has revolutionized the management of recurrent pleural effusions, and, in particular, those caused by malignancy. Apart from cases of mesothelioma, malignant pleural effusions (MPEs), by definition, represent metastatic disease and are hence associated with severely reduced survival times and limited curative options. Although survival can extend beyond 1 year, the majority of studies show that an average of 4-6 months can be expected [1], with patient mortality sometimes being measured in weeks from first diagnosis [2] depending on the tumor subgroup.

In the face of such aggressive disease, even a short period of hospitalization can immeasurably disrupt a patient's remaining quality of life, potentially invoking a sense of helplessness and disempowerment. With this in mind, it may be seen as frustrating that the traditional management options for MPE have been largely limited to inpatient procedures. Chemical pleurodesis, usually with sterile talc, attempts to prevent fluid recurrence over the medium- to long-term. In spite of being successful in the majority of cases [3], this approach often requires patients to remain in hospital for many days [4]. Continual and global increases in both direct costs and the burden on hospital resources mean that admission avoidance for MPE can lead to significant benefit for both patients and healthcare providers.

\section{KARGER}

E-Mail karger@karger.com

www.karger.com/res
IPCs have repeatedly been shown to be safe and well tolerated, with low levels of infection and high rates of symptomatic relief [5]. They also demonstrably reduce inpatient stays in both the long and short term $[6,7]$. Originally used as a fall-back device in cases of failed pleurodesis or trapped lung, there is a growing consensus that they can be offered to patients as a first-line treatment [7], effectively trading the idea of pleurodesis being the priority for an acceptance that it is occasionally in a patient's best interests to simply manage symptoms.

In this issue of Respiration, Boshuizen et al. [8] report a series of 50 IPCs, most of which were inserted as primary therapy for MPE. Echoing what has been reported before, their cohort demonstrates a significant reduction in both repeat pleural procedures and inpatient stay when compared to talc pleurodesis, alongside low rates of complications. Perhaps the most novel aspect of the study is the recording of the direct costs of IPC use in a European country - data which may help to more accurately determine the long-term cost-effectiveness of IPCs. The limited work in this area has consistently been based on costs and models of treatment from the USA [9-11], with flaws demonstrable in all studies. This current report also notes that there can be significant variability between the direct costs of using an IPC depending on disease subtype and cancer treatment success, highlighting once more the heterogeneity of survival amongst MPE patients and perhaps 
laying the groundwork for more accurate stratification of patients prior to treatment choices being offered.

For a small proportion of patients in the study, community nursing teams were called upon to perform regular drainage in the patient's home. Although this approach provides a tangible safety net for users - something which should be available to all patients - there is a danger that the prolonged use of IPCs in this way may lead to excessive costs. An important finding, therefore, was that in the Dutch model of healthcare it is feasible to have the majority of patients and families performing drainages themselves - a tactic which undoubtedly reduces long-term expenditure.
One of the most important roles of a physician in any condition is to provide a clear overview of a patient's treatment options, balancing this with the availability of local resources. Although there is much future work to be done on the full financial costs of using IPCs, current evidence would suggest that they are at least as good at relieving symptoms as the traditional methods of managing MPE [7], and may well be more cost-effective. We believe that the use of an IPC should be a joint decision between the patient and the clinician: this is a choice which has the potential to hand control of the disease back to those most directly affected.

\section{References}

$>1$ Heffner JE, Nietert PJ, Barbieri C: Pleural fluid $\mathrm{pH}$ as a predictor of survival for patients with malignant pleural effusions. Chest 2000; 117:79-86.

2 Clive AO, et al: S16 A large, prospective, multicentre study evaluating the survival of patients with malignant pleural effusion according to the underlying cell type. Thorax 2012; 67(suppl 2):A10-A11.

$>3$ Dresler CM, et al: Phase III intergroup study of talc poudrage vs. talc slurry sclerosis for malignant pleural effusion. Chest 2005;127: 909-915.

4 Yim AP, et al: Thoracoscopic talc insufflation versus talc slurry for symptomatic malignant pleural effusion. Ann Thorac Surg 1996;62: 1655-1658.
5 Van Meter MEM, McKee KY, Kohlwes RJ: Efficacy and safety of tunneled pleural catheters in adults with malignant pleural effusions: a systematic review. J Gen Intern Med 2011;26: 70-76.

6 Fysh ETH, et al: Indwelling pleural catheters reduce inpatient days over pleurodesis for malignant pleural effusion. Chest 2012;142: 394-400.

7 Davies HE, et al: Effect of an indwelling pleural catheter vs. chest tube and talc pleurodesis for relieving dyspnea in patients with malignant pleural effusion: the TIME2 randomized controlled trial. JAMA 2012;307:2383-2389.
$>8$ Boshuizen RC, Onderwater S, Burgers SJA, van den Heuvel MM: The use of indwelling pleural catheters for the management of malignant pleural effusion - direct costs in a Dutch hospital. Respiration 2013;86:224-228.

$>9$ Olden AM, Holloway R: Treatment of malignant pleural effusion: PleuRx catheter or talc pleurodesis? A cost-effectiveness analysis. J Palliat Med 2010;13:59-65.

10 Puri V, et al: Treatment of malignant pleural effusion: a cost-effectiveness analysis. Ann Thorac Surg 2012;94:374-379; discussion 379-380.

11 Michaud G, et al: Cost effectiveness analysis of strategies for managing malignant pleural effusions. Am J Respir Crit Care Med 2011; 183:A3082 (Meeting abstract). 